\title{
IDENTIFIKASI RESERVOAR DAERAH PANASBUMI DENGAN METODE GEOMAGNETIK DAERAH BLAWAN KECAMATAN SEMPOL KABUPATEN BONDOWOSO
}

\author{
Oleh: \\ Akhmad Afandi $^{1}$, Sukir Maryanto ${ }^{2}$, Arief Rachmansyah ${ }^{3}$
}

\begin{abstract}
ABSTRAK: Telah dilakukan penelitian tentang identifikasi reservoar panasbumi dengan metode geomagnetik daerah Blawan Kecamatan Sempol Kabupaten Bondowoso. Pengambilan data dilakukan dengan menggunakan alat Proton Precision Magnetometer (PPM-856), Global Positioning System (GPS) dan termometer. Luas area penelitian 1100 meter dan 650 meter dengan menggunakan spasi 50 meter. Pengolahan data menggunakan koreksi IGRF, diurnal, pengangkatan ke atas dan reduksi ke kutub yang berguna untuk memudahkan interpretasi. Nilai kontur anomali lokal sekitar -800 nT sampai $960 \mathrm{nT}$. Pemodelan 2 dimensi menggunakan metode talwani menghasilkan pola distribusi manifestasi panasbumi berasal dari Pegunungan Kendeng yang mengalir ke Blawan melalui celah atau patahan. Reservoar panasbumi belawan terjadi akibat adanya intrusi batuan gunungapi sehingga pada daerah tersebut memiliki nilai suseptibilitas yang rendah dan suhunya sangat panas. Potensi lokasi reservoar berada di penampang A-B pada kedalaman 889 meter dan D-E pada kedalaman 905 meter. Pemodelan 3 dimensi menghasilkan volume sebesar 133.16 juta $\mathrm{m}^{3}$, suhu reservoar $70.2^{\circ} \mathrm{C}$ dan rapat daya spekulatif $10 \mathrm{MW} / \mathrm{km} 2$ serta konversi energi $10 \%$.
\end{abstract}

Kata kunci: reservoar, anomali lokal, blawan, intrusi.

\begin{abstract}
Identification manifestations of geothermal reservoir area Blawan Sempol District Bondowoso regency has been observed based on geomagnetic method. Data were collected by using a Proton Precision Magnetometer (PPM-856), Global Positioning System (GPS) and a thermometer. The research area is 1.100 meters and 650 meters with 50 meter spacing between points. Data processing using IGRF correction, diurnal correction, upward continuation and reduction to the pole that is useful to facilitate interpretation. Value of Local Anomaly Contour in the range of $-800 \mathrm{nT}$ to 960 nT. 2 dimensional modeling using Talwani method generating distribution's pattern of geothermal derived from Kendeng volcano flowing into the Blawan through cracks or faults. Geothermal's reservoir occur due intrusion of volcanic rock so in the area have a low susceptibility value and temperature is very hot. Reservoir area prospect be in section drawing A-B at a depth of 889 meters and D-E at a depth 905 meters. 3 dimensional modeling of geothermal Blawan generating has a volume of 133.16 million $\mathrm{m}^{3}$, reservoir temperature is $70.2{ }^{\circ} \mathrm{C}$, speculative power density 10 $\mathrm{MW} / \mathrm{km}^{2}$ and energy conversion $10 \%$.
\end{abstract}

Keywords: reservoir, local anomaly, Blawan, intrusion.

\section{PENDAHULUAN}

Pertumbuhan jumlah penduduk yang meningkat menyebabkan kebutuhan energi meningkat tajam, sehingga diperlukan ketersediaan sumber energi yang baru. Untuk mencukupi kebutuhan tersebut dipenuhi dari energi yang ramah lingkungan.

Salah satu energi yang terbarukan dan ramah lingkungan yaitu energi panasbumi. Menurut Kebijakan Energi Nasional (Perpres No. 5 th 2006) kontribusi energi panas bumi

\footnotetext{
${ }^{1}$ Program Pasca Sarjana Jurusan Fisika, FMIPA, Universitas Brawijaya (email: fa2_exfo@yahoo.co.id)

${ }^{2}$ Jurusan Fisika, Fakultas MIPA, Universitas Brawijaya

${ }^{3}$ Jurusan Teknik Sipil, Fakultas Teknik, Universitas Brawijaya
} 
ditargetkan dalam bauran energi nasional sebesar $5 \%$ pada tahun 2025 atau sekitar 9500 MW. Untuk mewujudkan target tersebut telah disusun road map pengembangan energi panas bumi yang memberikan kerangka waktu bagi pencapaiannya. Keberadaan regulasi tersebut harus diikuti upaya-upaya dalam tataran teknis, antara lain penyiapan data-data panasbumi hasil kegiatan survei atau eksplorasi, yang nantinya digunakan penyiapan Wilayah Kerja Pertambangan (WKP) panas bumi [1].

Di Indonesia tercatat 256 daerah panas bumi yang berasosiasi dengan jalur Gunungapi Kuarter sebanyak $203(80 \%)$ dan $53(20 \%)$ berada di luar jalur tersebut. Dari daerah tersebut memiliki potensi 27.441 MW yang tersebar dari Nangroe Aceh Darussalam sampai Irian Jaya [1].

Salah satu daerah potensi panas bumi di Jawa Timur terletak di Blawan-Ijen, yang secara geografis terletak di 759'9"S - 114²10'32"E di desa Kalianyar, Kecamatan Sempol, Kabupaten Bondowoso. Keberadaan energi panasbumi ini ditunjukkan oleh kolam air panas dengan suhu air sekitar $39^{\circ} \mathrm{C}-51^{\circ} \mathrm{C}$ dan $\mathrm{pH}$ netral dan memiliki potensi yang besar.

Sebelum pemetaan eksplorasi perlu dilakukan survei pendahuluan dengan beberapa metode, salah satu metode tersebut yaitu metode geofisika. Dari beberapa metode geofisika (graviti, georadar, geomagnet dll), peneliti menggunakan metode geomagnet karena metode tersebut salah satu metode pasif, sensitif dan dapat menganalisa reservoar panasbumi dari besarnya intensitas magnet suatu batuan ditentukan oleh faktor kerentanan (susceptibilitas) magnet $k$ dari batuan tersebut, yaitu kemampuan dari suatu batuan dalam menerima sifat magnet dari medan magnet bumi. Kerentanan magnet $k$ suatu batuan sebanding dengan konsentrasi kelompok mineral magnetit di dalam batuan tersebut. Dengan kata lain batuan yang sedikit atau sama sekali tidak mengandung mineral magnetit, akan mempunyai intensitas magnet yang kecil, sehingga untuk batuan yang telah mengalami ubahan (alterasi) atau pelapukan, intensitasnya akan rendah [2].

\section{Akuisisi Data}

Dalam pengambilan data magnetik peneliti menggunakan metode lopping tertutup, dengan artian satu siklus pengukuran diawali dan diakhiri pada tempat yang sama. Hal ini bertujuan agar koreksi diurnal dapat dilakukan terhadap pengukuran. Kemudian titik-titik (spasi) diatur sejarak 50 meter antar titik pengambilan data, akan tetapi jarak antar titiktitik tersebut sewaktu-waktu bisa berubah dikarenakan titik-titik tersebut mengikuti jalurjalur yang memungkinkan untuk dilewati. Dari akuisisi data maka diperoleh 135 titik pengamatan dengan luasan 1100 meter dengan 650 meter. Penelitian ini dilakukan dengan pengambilan data nilai intensitas medan magnetik, waktu, posisi latitude, posisi longitude dan ketinggian di sekitar pemandian air panas Blawan dan suhu manifestasi panasbumi.

\section{HASIL DAN PEMBAHASAN}

\section{Interpretasi Kualitatif}

Interpretasi kualitatif bertujuan untuk melokalisir daerah benda anomali yang memiliki anomali yang rendah, sedang dan tinggi. Untuk memperoleh itu maka dilakukan beberapa koreksi, yaitu: koreksi harian (diurnal) yaitu koreksi yang dilakukan untuk 
mengurangi efek harian atau adanya matahari dan koreksi IGRF (Normal) yaitu koreksi untuk menghilangkan efek dari internal bumi dengan menggunakan nilai IGRF 44851.5 $\mathrm{nT}$, inklinasi $32.98^{\circ}$ dan deklinasi $1.37^{\circ}$. Anomali magnetik total merupakan plot dari hasil koreksi IGRF dengan posisi latitude dan longitude menggunakan metode kringing sehingga diperoleh seperti Gambar 1:

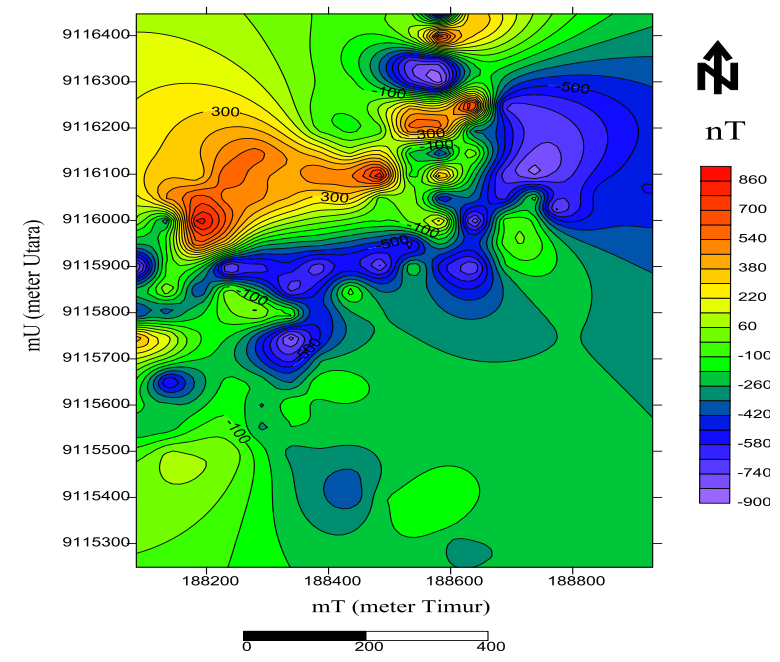

Gambar 1. Kontur anomali magnetik total

Dari Gambar 1 dapat dijelaskan bahwa perbedaan warna tersebut merupakan nilai intensitas magnet yang berkisar antara -900 nT untuk nilai minimum sampai 940 nT untuk nilai maksimum, pola positif dan negatif cenderung menuju ke arah utara dan selatan. Pola positif - negatif dan pola kontur agak merapat dapat diidentifikasikan bahwa daerah tersebut terdapat adanya patahan (sesar) [3]. Nilai anomali magnetik rendah memunyai nilai sekitar -900 nT sampai $0 \mathrm{nT}$, anomali magnetik sedang -260 nT sampai $220 \mathrm{nT}$ dan anomali magnetik tinggi $380 \mathrm{nT}$ sampai $940 \mathrm{nT}$.

Agar mempercepat hasil agar divergensi maka ketinggian harus dibawa ke tengah topografi penelitian [4]. Dimana, topografi daerah penelitian berada pada ketinggian sekitar 911 sampai 1040 meter diatas permukaan laut (mdpl), maka kontur anomali magnetik total pada level topografi harus dibawa pada ketinggian 955 meter diatas permukaan laut (mdpl) atau hasil rata-rata pada topografi daerah penelitian. Dengan hasil seperti Gambar 2:

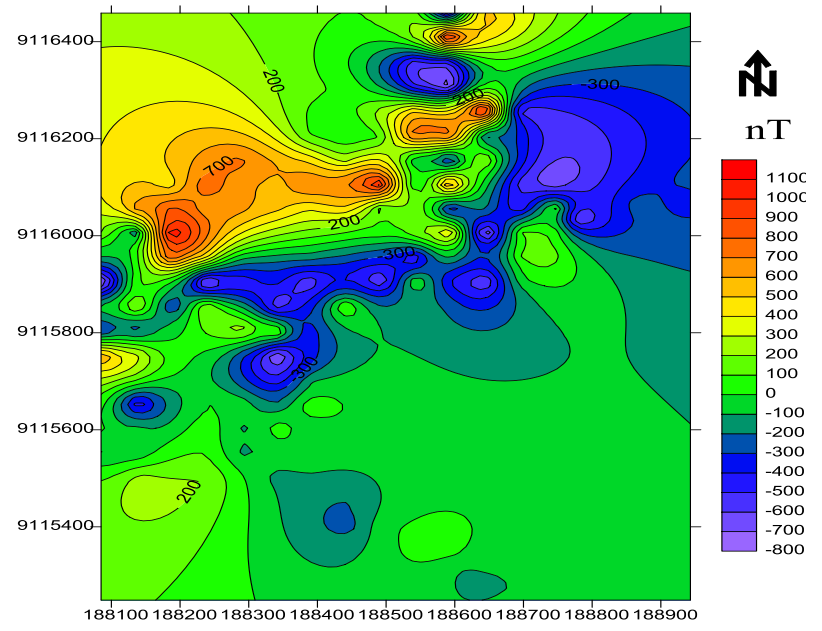

Gambar 2. Kontur anomali hasil reduksi ke bidang datar 
Untuk memisahkan antara anomali regional dan anomali lokal perlu dilakukan filtering yaitu dengan kontinuasi ke atas. Kontinuasi ke atas merupakan tranformasi dari bidang datar ke level yang lebih tinggi [5]. Pada kontinuasi ke atas dilakukan dengan sistem trial and error pada ketinggian $100 \mathrm{~m}$ hingga $1100 \mathrm{~m}$, sampai diperoleh anomali regional mengalami pelemahan (Gambar 3). Hasil dari kontinuasi ke atas diperoleh pada ketinggian $1000 \mathrm{~m}$.

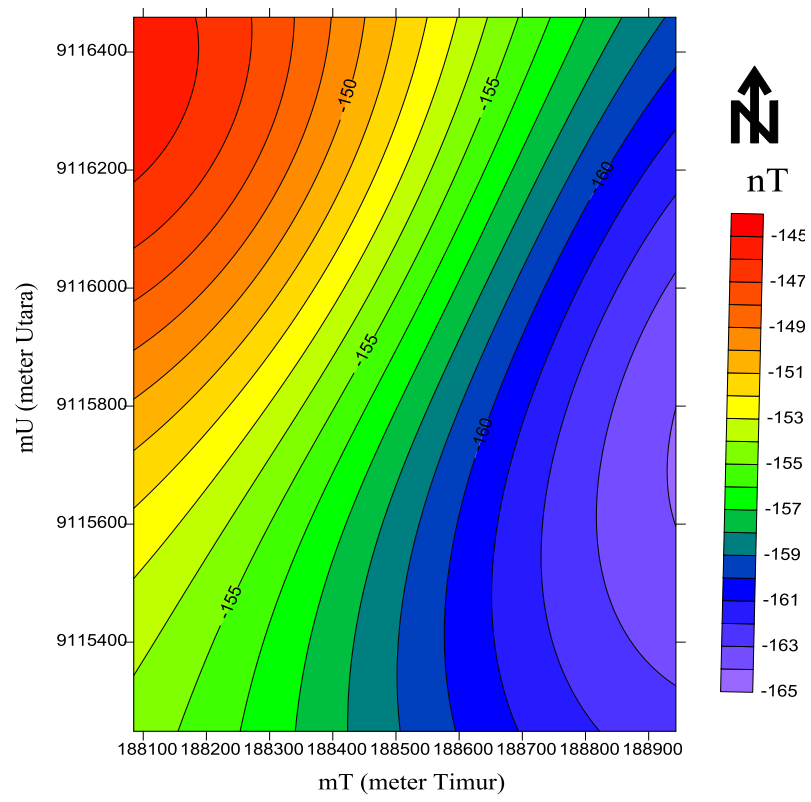

Gambar 3. Kontur anomali regional

Anomali lokal diperoleh dari pengurangan anomali magnet total terhadap anomali regional. Hasil anomali lokal seperti Gambar 4, pada Gambar 4 dapat dijelaskan bahwa nilai magnetiknya berkisar antara - $800 \mathrm{nT}$ sampai $1200 \mathrm{nT}$.

Pada survei panasbumi anomali yang dicari yaitu anomali rendah hal ini dikarenakan adanya proses demagnetisasi oleh alterasi hidrotermal sehingga mineral dari suatu batuan menjadi mineral paramagnetik bahkan diamagnetik [6].

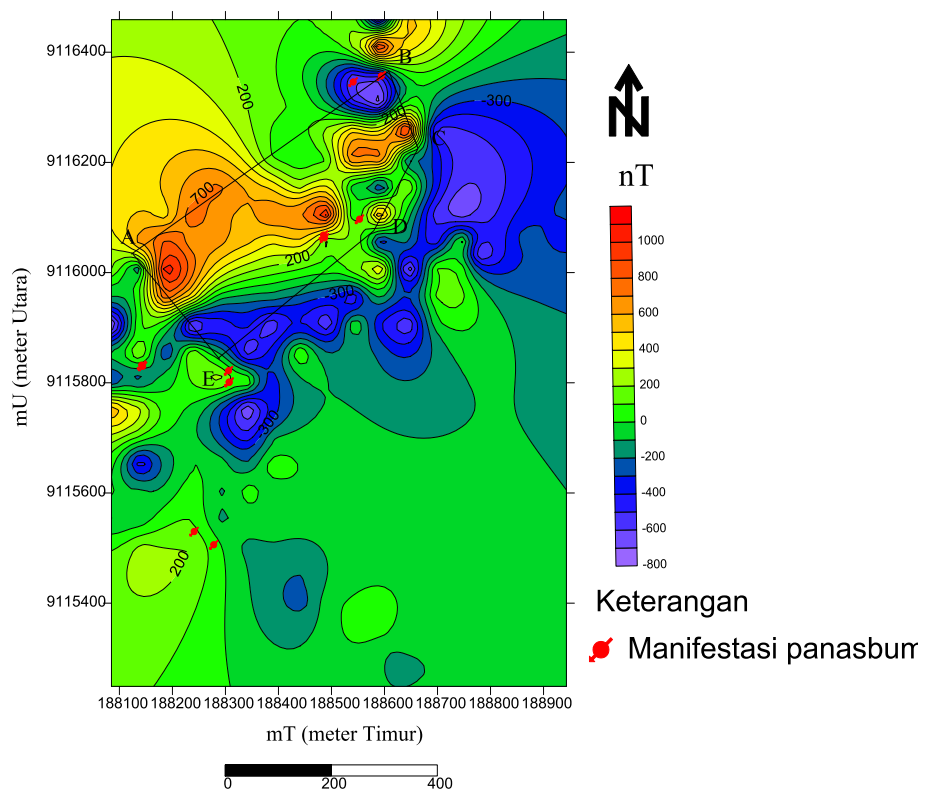

Gambar 4. Kontur anomali lokal 


\section{Interpretasi Kuantitatif}

Interpretasi kuantitatif dilakukan pemodelan dengan menggunakan 2 dimensi dan 3 dimensi. Pemodelan 2 dimensi mengambil data dari anomali lokal yang sudah di sayat (lihat Gambar 4), dimana metode pemodelan 2 dimensi ini diajukan oleh Talwani dimana hasil dari pemodelan ini adalah variabel lebar, kedalaman dan ketebalan.

Dalam interpretasi kuantitatif ini masih terdapat adanya ambiguitas, untuk mengurangi ambiguitas tersebut maka perlu adanya data yang mendukung seperti peta geologi, tabel suseptibilitas batuan dan pendukung lainnya.

Pemodelan dengan sayatan A-B (Gambar 5) terdapat pola positif-negatif dikarenakan medan magnet mempunyai pasangan dipole, dimana nilai intensitas magnet positf dikarenakan adanya batuan yang bersifat ferromagnet dan pola negatif termasuk batuan yang bersifat diamagnetik. Pada Gambar 5 terdapat adanya intrusi pada kedalaman 1095 meter pada level topografi, dimana hasil intrusi ini mengakibatkan batuan sekitar mempunyai nilai suseptibilitas rendah dan dapat disimpulkan bahwa terdapat reservoar. Hal ini ditandai dengan adanya beberapa manifestasi panasbumi pada daerah tersebut.

Pemodelan dengan sayatan B-C (Gambar 6) terdapat pola positif-negatif dan adanya intrusi sehingga mengakibatkan batuan disekitar menjadi rendah dan dapat disimpulkan bahwa intrusi tersebut adalah reservoar karena memiliki nilai suseptibilitas yang rendah pada kedalaman 1456 meter pada level topografi.
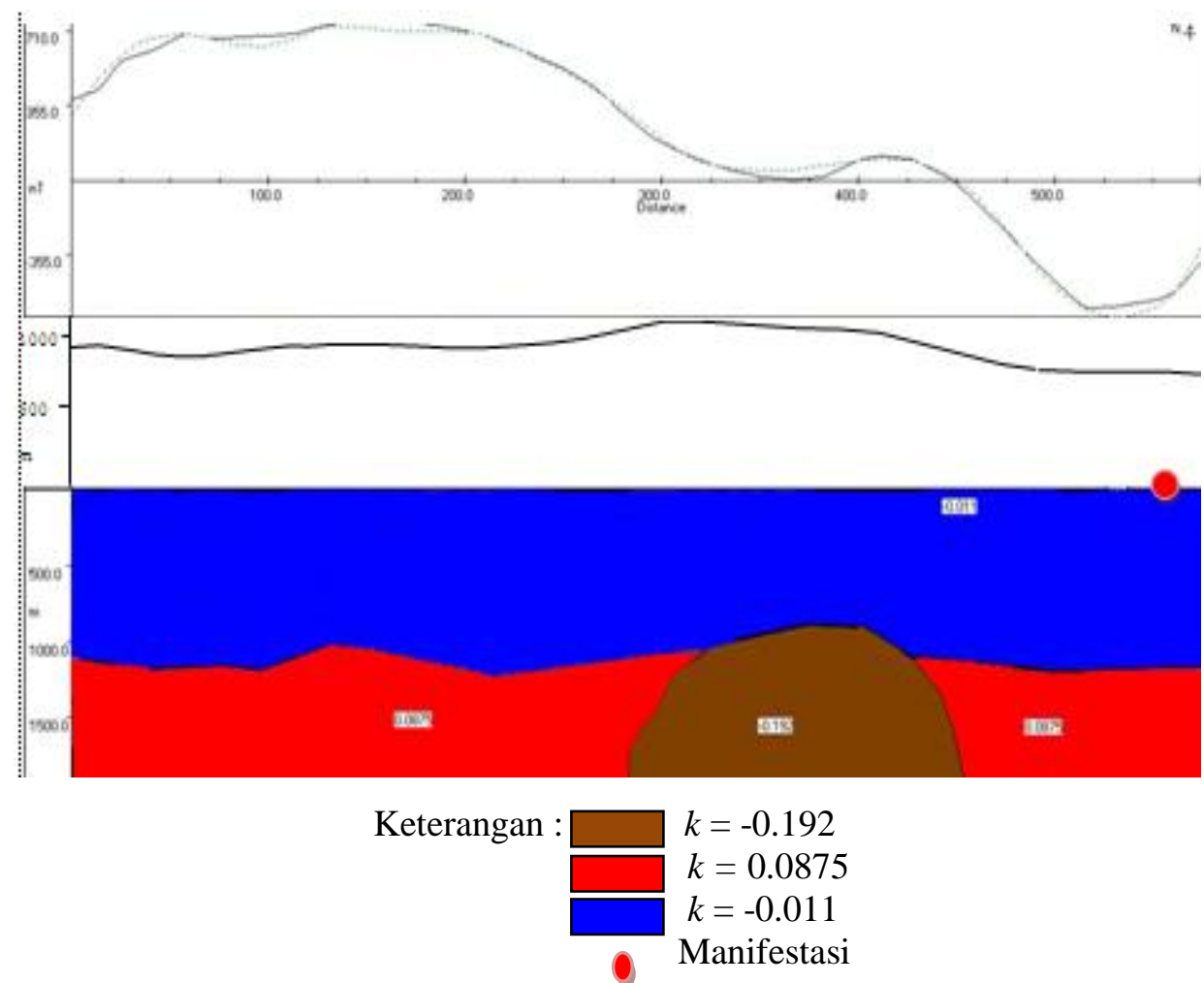

Gambar 5. Penampang sayatan A-B 


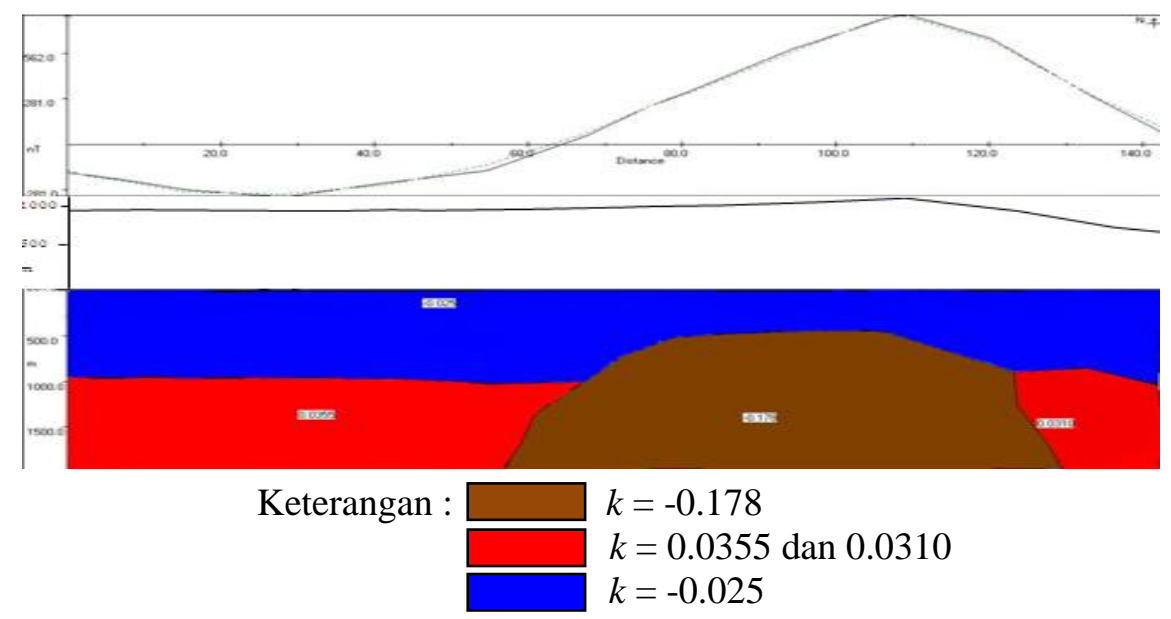

Gambar 6. Penampang sayatan B-C

Pemodelan dengan sayatan C-D (Gambar 7) terdapat juga pola positif-negatif (dipole) dan terdapat sebuah sesar yang terjadi pada pada jarak 26 meter pada kedalaman 0 sampai 530 meter dari arah timur laut menuju barat daya. Sehingga, sesar tersebut menjadi salah satu saluran air panas yang muncul dipermukaan (manifestasi). Dari Gambar 7 juga terdapat intrusi magma yang mengakibatkan batuan sekitar mempunyai nilai suseptibilitas rendah dan dapat disimpulkan bahwa terdapat reservoar pada kedalaman 1068 meter pada level topografi.

Pemodelan dengan sayatan D-E (Gambar 8) juga terdapat pola positif-negatif (dipole), dimana nilai intensitas magnet positf dikarenakan adanya batuan yang bersifat ferromagnet dan pola negatif termasuk batuan yang bersifat diamagnetik. Dari Gambar 8 terdapat adanya intrusi, sehingga dapat disimpulkan bahwa intrusi tersebut adalah reservoar karena memiliki nilai suseptibilitas yang rendah pada kedalaman 1889 meter dari level topografi.

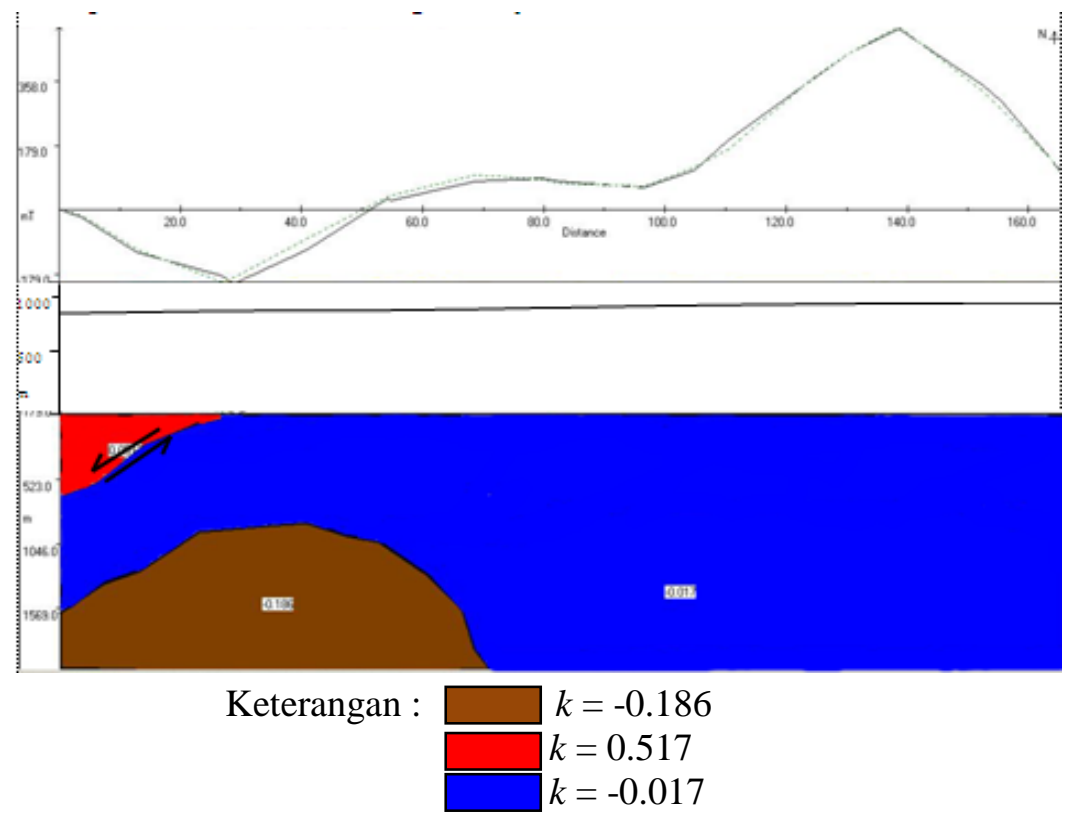

Gambar 7. Penampang sayatan C-D 


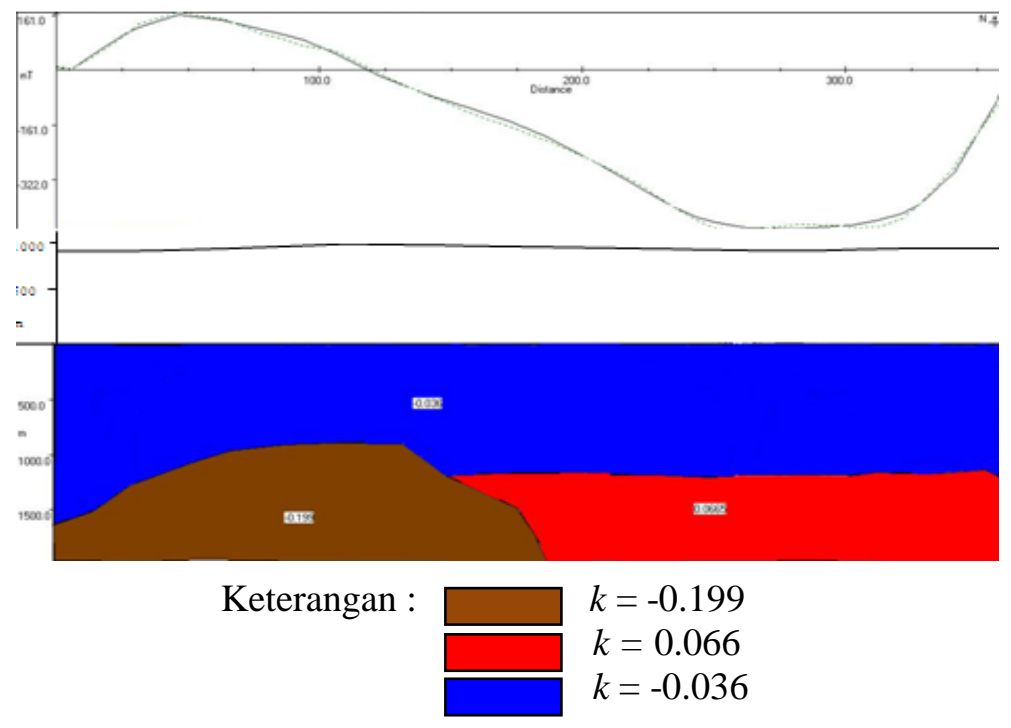

Gambar 8. Penampang sayatan D-E

Pemodelan dengan sayatan C-D (Gambar 7) terdapat juga pola positif-negatif (dipole) dan terdapat sebuah sesar yang terjadi pada pada jarak 26 meter pada kedalaman 0 sampai 530 meter dari arah timur laut menuju barat daya. Sehingga, sesar tersebut menjadi salah satu saluran air panas yang muncul dipermukaan (manifestasi). Dari Gambar 7 juga terdapat intrusi magma yang mengakibatkan batuan sekitar mempunyai nilai suseptibilitas rendah dan dapat disimpulkan bahwa terdapat reservoar pada kedalaman 1068 meter pada level topografi.

Pemodelan dengan sayatan E-A (Gambar 9) juga terdapat pola positif-negatif (dipole) dan Selain itu juga terdapat sebuah patahan pada jarak 80 meter dari arah timur laut menuju barat daya. Dari Gambar 9 juga terdapat adanya intrusi magma, sehingga dapat disimpulkan bahwa intrusi tersebut adalah reservoar karena memiliki nilai suseptibilitas yang rendah pada kedalaman 1856 meter dari level topografi.

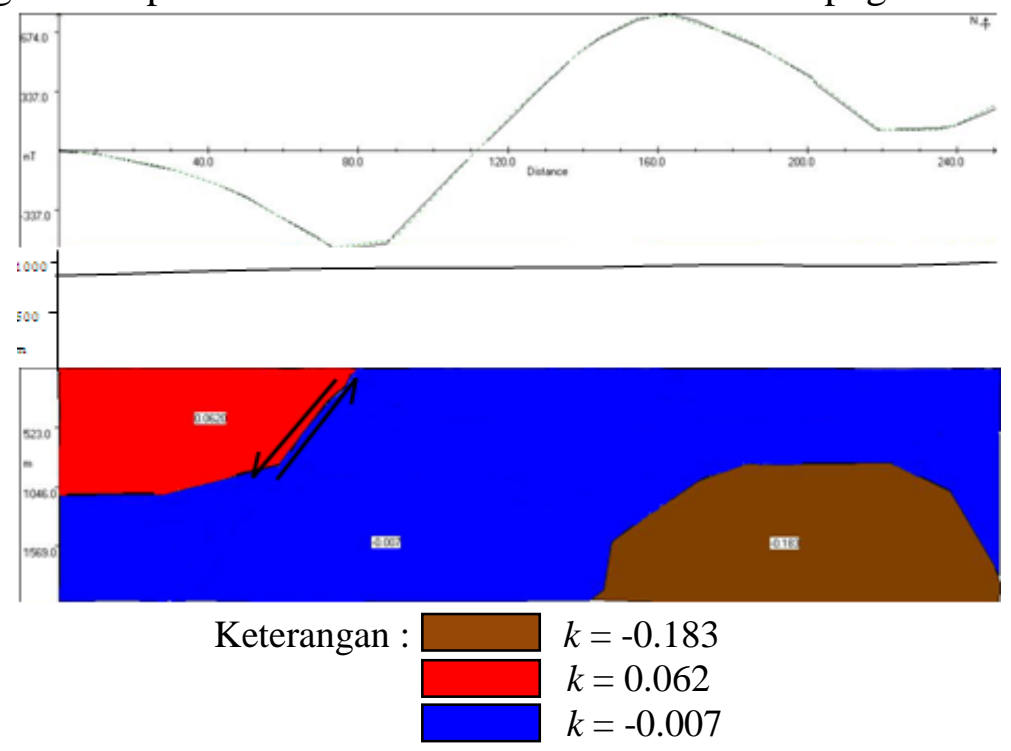

Gambar 9. Penampang sayatan E-A 
Suatu fluida yang memiliki material tertentu akan lebih melepas material tersebut jika terkana perubahan suhu yang meningkat, sehingga material akan berubah yang semula memiliki nilai suseptibilitas yang tinggi menjadi rendah. Dimana fluida sebagai reservoar yaitu berada sekitar kedalaman 500 sampai 2000 meter dan di daerah tersebut juga banyak patahan yang dapat diperkirakan sebagai media aliran air panas. Patahan terdapat di Gambar 7 dan Gambar 9 berada disekitar sumber air panas, dengan menarik lurus ke arah timur laut patahan tersebut akan menuju Pegunungan Kendeng (Gambar 10) [7]. Dimana Pegunungan Kendeng merupakan pegunungan kaldera ijen tua [8], hal ini sangat memungkinkan bahwa sumber air panas Blawan berasal kaldera ijen tua yang menyebar ke arah pegunungan kendeng.

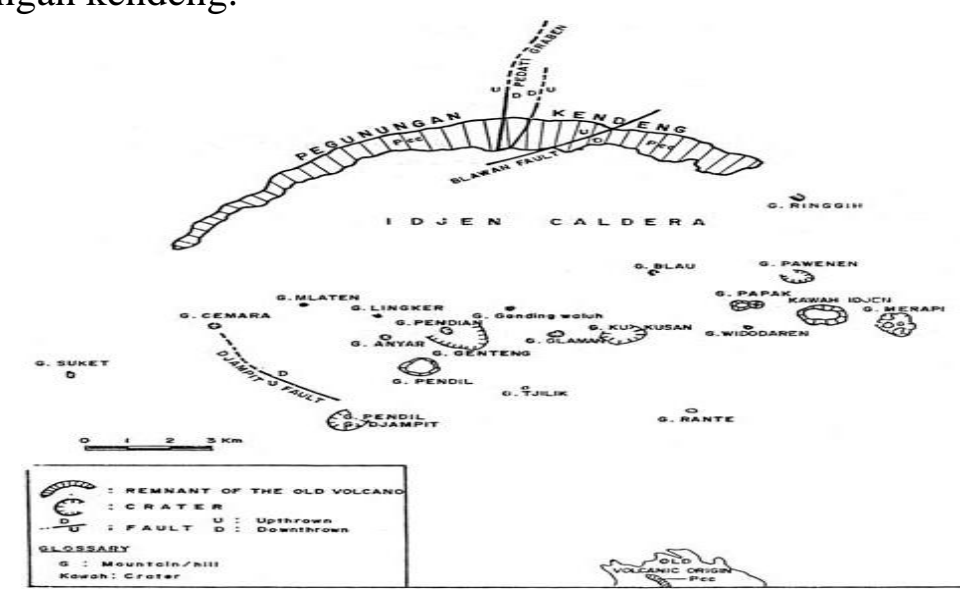

Gambar 10. Patahan Blawan [7]

Dari pemodelan tersebut daerah yang paling berpotensi yaitu pada lokasi sayatan B$\mathrm{C}$ dan D-E karena batuan reservoarnya memiliki suseptibilitas yang rendah sehingga suhu yang dimiliki batuan tersebut semakin panas.

Hasil dari semua pemodelan 2 dimensi jika dilihat dengan rockwork secara 3 dimensi seperti Gambar 11 dan Gambar 12. Jika kedua gambar tersebut diinterpolasikan pada sebuah kubus maka dapat dihasilkan Gambar 13 dan Gambar 14

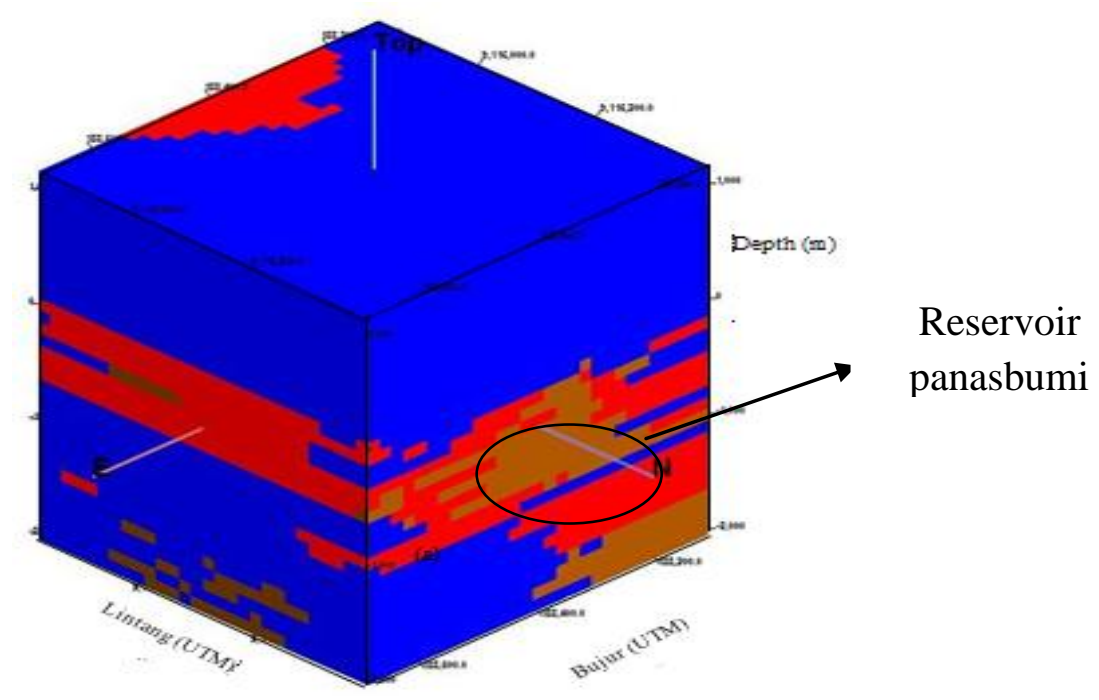

Gambar 11. Model 3 Dimensi model lapisan batuan daerah panasbumi Blawan dilihat dari arah utara dan timur 


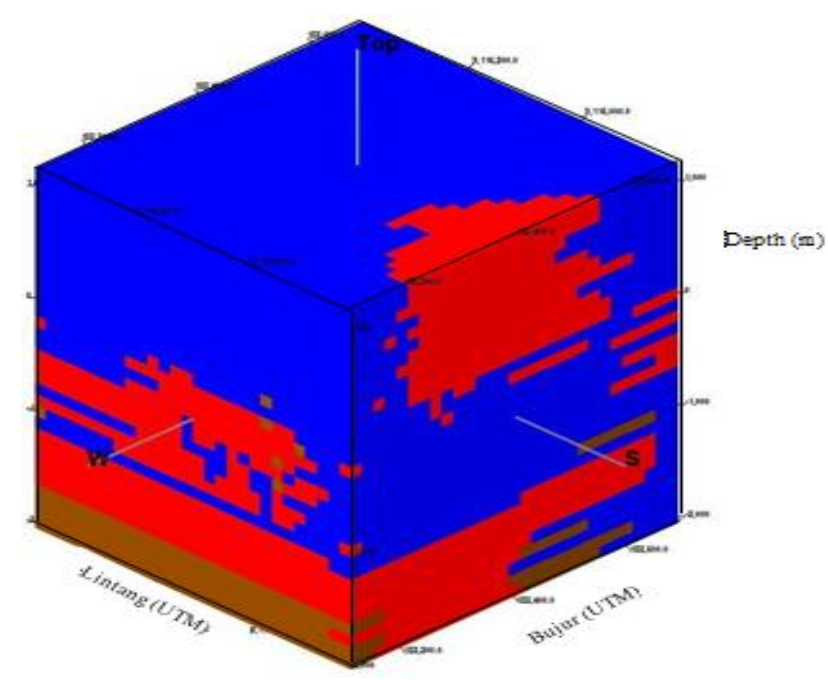

Gambar 12. Model 3 Dimensi model lapisan batuan daerah panasbumi Blawan dilihat dari arah barat dan selatan

Dari pemodelan Gambar 11 dan 12 daerah permukaan didominasi oleh warna biru, sedangkan untuk reservoarnya yaitu ditunjukkan dengan warna coklat karena memiliki nilai suseptibilitas yang rendah sehingga bisa dikatakan suhu reservoar tesebut bertambah panas.

Untuk volume reservoarnya secara total dari pemodelan tersebut secara inversi menggunakan rockwork sebesar 133.16 juta $\mathrm{m}^{3}$, sedangkan mencari suhu reservoarnya dengan cara mengambil rata-rata suhu manifestasi di Blawan yaitu sekitar $43^{\circ} \mathrm{C}$ dan mengasumsikan bahwa setiap kedalaman memiliki suhu $30^{\circ} \mathrm{C} / \mathrm{km}$ [9]. Maka, suhu reservoar yang berpotensi di daerah panasbumi Blawan pada lokasi A-B di kedalaman 1900 meter sekitar $100.2^{\circ} \mathrm{C}$ dan lokasi D-E di kedalaman 1890 meter sekitar $100.1^{\circ} \mathrm{C}$. Menurut Herman (2012) pada suhu $<150^{\circ} \mathrm{C}$ masuk pada katagori rapat daya spekulatif 10 $\mathrm{MW} / \mathrm{km}^{2}$ dan konversi energi $10 \%$ [10].

\section{KESIMPULAN}

Berdasarkan penelitian ini dapat disimpulkan, bahwa distribusi manifestasi panasbumi Blawan berasal dari kaldera ijen tua menyebar ke arah Pegunungan Kendeng melalui patahan Blawan (Blawan fault). Reservoar panasbumi terdapat pada batuan gunungapi dan lokasi yang potensi yaitu pada A-B berada pada kedalaman sekitar 1900 meter memiliki suhu sekitar $100.2^{\circ} \mathrm{C}$ dan D-E berada pada kedalaman sekitar 1890 meter memiliki suhu sekitar $100.1^{\circ} \mathrm{C}$. Reservoar tersebut ditunjukkan oleh nilai suseptibilitas rendah. Reservoar panasbumi di Blawan mempunyai volume sekitar 133.16 juta $\mathrm{m}^{3}$ dengan rapat daya spekulatif $10 \mathrm{MW} / \mathrm{km}^{2}$, sehingga hanya dikonversi $10 \%$.

\section{DAFTAR PUSTAKA}

[1] Kasbani, Suhanto, E., Dahlan, 2005. Kesiapan Data Potensi Panas Bumi Indonesia Dalam Mendukung Penyiapan Wilayah Kerja. Kelompok Program Penelitian Panas Bumi. Pusat sumber daya geologi. 
[2] Foeh, I. A., dan Lilirk, R. R., 2005. Penyelidikan Geomagnetik di Daerah Panas Bumi Kanan Tedong di Desa Pincara Kecamatan Masamba Kabupaten Luwu Utara Propinsi Sulawesi Selatan. Pemaparan Hasil Kegiatan Lapangan Subdit Panas Bumi.

[3] Idral, A., 2005. Hasil Penyelidikan Geomagnit Daerah Panas Bumi Suwawa Kab.Bone Bolango - Propinsi Gorontalo. Pemaparan Hasil Kegiatan Lapangan Subdit Panas Bumi, Subdit Panas Bumi - Dim.

[4] Blakely, R.J., 1995. Potential Theory in Gravity and Magnetic Applications. Cambridge University Press. New York.

[5] Telford, W.M., Geldart, L.P., Sheriff, R.E., 1990. Applied Geophysics. Cambridge University Press. Ambridge.

[6] Indratmoko, P., Irham M. N., Tony Y., 2009. Interpretasi Bawah Permukaan Daerah Manifestasi Panasbumi Parang Tritis Kabupaten Bantul DIY Dengan Metode Magnetik, Berkala Fisika.Vol. 12, No. 4, Oktober 2009, ISSN : $1410-9662$.

[7] Sitorus, K., 1990. Volcanic Stratigraphy and Geochemistry of Ijen Caldera complex, East-Java, Unpublished, Master Thesis, Victoria University of Wellington, New Zealand.

[8] Zainnuddin, A., Deden, W., Mamay S., Kusdinar, E., 2012. Prakiraan bahaya letusan Gunung Api Ijen Jawa Timur. Jurnal Lingkungan dan Bencana Geologi, Vol. 3 No. 2 Agustus 2012: 109-132.

[9] Suparno, S, 2009. A Present from The Heart of The Earth, FMIPA-UI, Jakarta.

[10] Herman, Z.D., 2012. Potensi Panas Bumi Dan Pemikiran Konservasinya. Sub Direktorat Konservasi - DIM. Pusat Sumber Daya Geologi, Jawa Barat. http://www.psdg.bgl.esdm.go.idindex.phpoption=com_content\&view=article\&id=38 3\&Itemid=395. Tanggal akses: 30 Juli 2013. 